\title{
Gout, obesity and bariatric surgery
}

\begin{abstract}
Gout is a common arthritis disease, characterized by high serum levels of uric acid. The disease is associated with many co-morbidities, such as: hypertension, type 2 diabetes, ischemic heart disease, kidney disease and obesity, and even has an impact on mortality. It appears as a form of arthritis, characterized by joint inflammation, commonly occurring in the first metatarsophalangeal joint.

Abdominal adiposity, obesity, as well as metabolic syndrome were all found to be associated with the increased risk of developing gout. Weight loss, associated with a reduction in serum urate levels, was found to lower incidence of gout. Many studies have demonstrated that weight loss following bariatric surgery resulted in reduced serum uric acid levels. Nevertheless, some studies have demonstrated that immediately after the surgical procedure, a significantly higher frequency of gout attacks was observed, which was significantly decreased after the first postoperative month up to 1 year. Thus, it is recommended that preoperative prophylactic treatment should be administered to patients with a history of gout and that serum uric acid levels should be followed shortly after the surgery to prevent an increase in the incidence of gout attacks.
\end{abstract}

Volume 8 Issue 4 - 2018

\author{
Asnat Raziel \\ Assia Medical Group, Assuta Medical Center, Israel
}

Correspondence: Asnat Raziel,Assia Medical Group, Assuta Medical Center, 20 Habarzel Street, Tel Aviv, 6971028, Israel, Tel +972-52-4261 103, Email doctor@asnatraziel.com

Received: June 26, 2018 | Published: August 0I, 2018

\section{Introduction}

Gout is a common arthritis disease, characterized by high serum levels of uric acid. Many risk factors were found to contribute to the development of the disease. Accumulated evidence has pointed out that gout is highly associated with obesity and metabolic syndrome. Moreover, it has been demonstrated by various clinical studies that upon major weight loss, the risk for the development of gout, as well as the frequency of attacks are reduced in correlation with a reduction in the serum uric acid levels.

In this review we will present the association between high levels of serum uric acid, gout and obesity. The beneficial effects of weight loss, especially by bariatric surgery, will be discussed.

\section{Gout disease}

Gout is both an inflammatory and a metabolic disease. It is accompanied by significant pain, functional impairment, increased work absence causing reduced productivity, reduced quality of life and presents an economic burden for the individual and the community. ${ }^{1-3}$ The disease is associated with co-morbidities, and even has an impact on mortality. ${ }^{4}$

\section{Symptoms}

Acute gout appears as a form of arthritis, characterized by joint inflammation, commonly occurring in the first metatarsophalangeal joint, reaching maximal intensity within 24 hours. Involvement of the inter-tarsal, ankle and knee joints is also common, while the involvement of hand, wrist and olecranon bursal is present only in patients who have been suffering from the disease for manyyears. ${ }^{5}$

Gout is mostly diagnosed by its clinical presentation of swelling and redness of the first metatarsophalangeal joint. The American College of Rheumatology criteria are the most widely used guidelines for diagnosis of gout and include: Presence of characteristic urate crystals in the joint fluid, asymmetric swelling within a joint on radiography, attack of mono-articular arthritis, negative culture of joint fluid for microorganisms during attack of joint inflammation, development of maximal inflammation within one day, hyperuricemia, joint redness, more than one attack of acute arthritis, as well as pain or redness in the first metatarsophalangeal joint and subcortical cysts without erosions on radiography. The disease is usually followed with hyperuricemia, defined as a plasma urate level higher than $420 \mu \mathrm{mol} / 1(7.0 \mathrm{mg} / \mathrm{dl})$ in males and $360 \mu \mathrm{mol} / 1(6.0 \mathrm{mg} / \mathrm{dl})$ in females. ${ }^{6}$

\section{Pathogenesis}

Gout is caused by prolonged high serum levels of uric acid, possibly caused by inactive uricase, the enzyme responsible for the breakdown of uric acid to allantoin or by impairment of renal excretion. The balance between uric acid production and excretion determines its serum concentrations. High serum levels of uric acid appear to contribute to impaired nitric oxide production, endothelial dysfunction, increased vascular stiffness, inappropriate activation of the renin-angiotensin-aldosterone system, enhanced oxidative stress, and maladaptive immune and inflammatory responses. ${ }^{7}$ Furthermore, hyperuricemia may not be benign and appears to be accompanying the worldwide obesity pandemic, metabolic syndrome, hypertension, diabetes and kidney and cardiovascular disease states. ${ }^{8}$

As a result of high serum uric acid levels, monosodium urate (MSU) crystals are formed, inducing local and a systemic inflammatory response, resulting in the activation of caspase- 1 , interleukin $-1 \beta$ and 6 , tumor necrosis factor $\alpha$, and neutrophil chemotactants. ${ }^{5,9}$ Consequently, enormous amounts of neutrophils are recruited to the joint, sustaining the inflammatory response and inducing damage in the surrounding tissues. ${ }^{10}$

However, it is important to mention that the majority of people with hyperuricemia do not have gout. Nevertheless, the risk of gout raises with the increasing serum urate levels. In addition, the comorbidities of gout, renal and cardiovascular diseases, are commonly associated with asymptomatic high levels of serum uric acid. ${ }^{11}$

\section{Frequency}

The prevalence of gout is increasing worldwide, probably due to population aging, changes in diet and lifestyle, and increasing rates of obesity. ${ }^{12-15}$ In the population under 65 years of age, males have a fourfold higher prevalence of gout than females. However, this ratio is reduced to 3:1 male to female over 65 years of age. ${ }^{13}$ The mean age of gout onset is approximately 10 years older in females than males, 
probably due to the estrogen's protection effect - enhancing the renal tubular urate excretion in pre-menopausal females. ${ }^{16}$

\section{Risk factors}

Overweight and obesity, metabolic syndrome, hypertension, high levels of blood cholesterol and chronic kidney disease have been associated with increased risk of gout. ${ }^{17}$ Obesity was found in many prospective cohort studies as one of the strongest risk factor for hyperuricemia and gout. ${ }^{18-22}$

Additional risk factors include: Increasing age; Genetic Factors such as: SLC22A12-SLC22A12 which encodes urate anion transporter 1, SLC2A9-SLC2A9 encoding glucose transporter type 9, and BCG2 which encodes the adenosine triphosphate binding transporter 2. Mutation in these genes, which are involved in renal urate transport, were found in gout patients and may explain certain subjects' predisposition for developing hyperuricemia and gout ${ }^{23}$ alcohol consumption, especially beer and liquor: ${ }^{24}$ increased consumption of meat and seafood; ${ }^{25}$ fructose intake; ${ }^{26}$ use of diuretics; and taking various medications such as $\beta$-blockers and angiotensin-II receptor antagonists. ${ }^{27}$

On the other hand, low fat dairy products, coffee, supplementation of vitamin $\mathrm{C}$ and cherry consumption have been shown to be potentially protective against the development of gout by acutely lowering serum uric acid. ${ }^{23}$ Calcium-channel blockers and losartan appear to reduce the risk of developing hyperuricemia and gout. ${ }^{27}$

Diabetes, hypertriglyceridemia and hypercholesterolemia are associated with significantly increased risk of gout flares in patients with prevalent gout. ${ }^{28}$

\section{Co-morbidities}

Gout is associated with a number of serious co-morbidities, such as: hypertension, type 2 diabetes, ischemic heart disease, kidney disease and obesity. ${ }^{29}$ It is also associated with premature death due to a high frequency of comorbidities. ${ }^{30}$ Indeed, increased risk of death in gout patients with renal dialysis and cardiovascular diseases has been demonstrated. ${ }^{31-34}$ A recent meta-analysis of six studies revealed that the prevalence of chronic kidney disease of stage 3 or above in gout was estimated at $24 \%{ }^{35}$ Gout was found to be associated with a high risk of coronary heart disease, heart failure, atrial fibrillation, aortic stenosis, ischemic stroke and peripheral vascular disease. ${ }^{36}$ Moreover, drugs targeting those comorbidities were found to be associated with increased risk of gout. ${ }^{37} \mathrm{In}$ addition to that, links between increased serum levels of uric acid and brain dysfunction, low performance on memory-related tasks, as well as age-related illnesses and Parkinson's disease have been reported. ${ }^{38}$

The prevalence of metabolic syndrome is $62.8 \%$ in patients with gout, compared with $25.4 \%$ in non-gout patients. In the third National Health and Nutrition Examination Survey (NHANES) the prevalence of abdominal obesity was found to be $62.9 \%$ in gout patients vs. $35.3 \%$ in non-gout patients. ${ }^{39}$

Co-morbidities can also be a contraindication for drugs used in the management of acute flares of gout disease. For example, in patients with renal failure, colchicine and NSAIDs should not be used. ${ }^{40}$

\section{Treatment}

The American College of Physicians developed guidelines providing clinical recommendations for the management of gout.
The recommendations are based on a systematic review of various randomized, controlled trials; systematic reviews; and large observational studies published between January 2010 and March 2016.

The treatment of gout patients is aimed to lower serum uric acid in order to allow MSU crystals to dissolve and to prevent the creation of further MSU in the joints, as well as to relieve the inflammation symptoms. According to the European League against Rheumatism (EULAR), non-steroidal anti-inflammatory drugs (NSAIDs) or colchicine are considered as first-line agents for the treatment of acute gout attacks and should begin as soon as possible. Oral or intra-articular corticosteroids are recommended for those who cannot tolerate the above medications, or who have contraindications. ${ }^{41}$ In patients with frequent attacks and contraindications to colchicine, NSAIDs and corticosteroids, interleukin-1 blocker should be considered. ${ }^{42}$

Allopurinol, used to decrease high blood uric acid levels, should be started during an acute attack (at 50-100mg per day or less for those with severe renal impairment) and should last until suitable serum uric acid levels, monitored every two to five weeks, are maintained. ${ }^{29}$ However, according to the American College of Physicians long-term urate-lowering therapy is not recommended after a first gout attack or in patients with infrequent attacks. ${ }^{43}$ If a decreased level of serum uric acid cannot be achieved with allopurinol, then febuxostat, a uricosuric drug or a combination of a xanthine oxidase inhibitor with a uricosuric drug should be considered. For patients with refractory gout, pegloticase is recommended. ${ }^{42}$ Weight control appears to lower serum uric acid levels, thus the role of diet plays a very important part in gout management. ${ }^{44}$ According to the British Society for Rheumatology Guideline for the Management of Gout from 2017, a well-balanced low in fat and sugars diet, and high in vegetables and fiber should be encouraged; excessive intake of alcoholic drinks and high purine foods should be avoided; inclusion of soy beans and vegetable sources of protein, and cherries in the diet are recommended. ${ }^{45}$

\section{Obesity and gout}

Overweight and obesity are becoming endemic and are associated with insulin resistance, type 2 diabetes, dyslipidemia , hypertension, cholelithiasis, various malignances, non-alcoholic steatohepatitis, gastro-esophageal reflux, obstructive sleep apnea, degenerative joint disease, lower back pain, polycystic ovary syndrome, as well as a remarkable reduction in life expectancy. ${ }^{46}$

Abdominal adiposity, obesity, as well as weight gain were all found to be associated with the increased risk of developing gout. ${ }^{20,47,48}$ Men with a Body mass index (BMI) over $27.5 \mathrm{~kg} / \mathrm{m}^{2}$ were 16 times more likely to report gout attacks than men with a BMI $<20 \mathrm{~kg} / \mathrm{m}^{2}{ }^{29}$

Interestingly, the risk of recurrent gout attacks and its association to obesity have been contradictory. Zhang et al., ${ }^{50}$ reported that there was no association between BMI and the risk of recurrent attacks of gout. ${ }^{50}$ Cea Soriano et al. ${ }^{51}$ compared a large British data base of newly diagnosed gout patients with matched controls and discovered a significantly reduced association between obesity and recurrent gout attacks than between obesity and the risk of gout development. In contrast, Nguyen has shown that a decrease in BMI reduced the risk of recurrent attacks of gout, while an increase in BMI augmented the risk of recurrent attacks of gout, suggesting that this could be a better tool to evaluate the association between obesity and the recurrence of gout attacks. ${ }^{52}$ 
Many studies have demonstrated that weight reduction upon low-calorie diets leads to reduced serum uric acid levels in people with obesity. ${ }^{53}$ Weight loss, associated with a reduction in serum urate levels, was also found to lower incidence of gout. ${ }^{25}$ Nielsen et al., ${ }^{41}$ performed a systematic review and found out that a weight loss of $>7 \mathrm{~kg}$ resulted in a beneficial effect on serum uric acid at medium-term/long-term follow-up and that weight loss of $>3.5 \mathrm{~kg}$ showed beneficial effects on gout attacks on medium-term/long-term follow-up. ${ }^{54}$ Hence, The American College of Rheumatology and the European League against Rheumatism guidelines recommend weight loss for gout management in obese subjects. ${ }^{41}$

\section{Bariatric surgery and gout}

Bariatric surgery is currently the most effective intervention for weight loss and long-term weight maintenance. This has been consistently demonstrated in numerous randomized controlled trials and cohort studies. ${ }^{55,56}$ Bariatric surgery is a safe and effective tool to achieve a marked weight loss. The eligibility criteria for accessing bariatric surgery includes the following: $\mathrm{BMI} \geq 40 \mathrm{~kg} / \mathrm{m}^{2}$ or a BMI between 35 and $39.9 \mathrm{~kg} / \mathrm{m}^{2}$ with comorbidity and previous unsuccessful weight loss efforts. ${ }^{57}$ The rates of bariatric surgery procedures are increasing sharply. The surgical procedure usually results in a weight loss of $20-40 \mathrm{~kg}$ and a $10-15 \mathrm{~kg} / \mathrm{m}^{2}$ reduction in BMI. ${ }^{58}$ Weight loss is maximal after 1-2 years and the weight slowly increases until year $8-10$ after which body weight stabilizes. ${ }^{59}$

The common types of weight-loss surgery are laparoscopic Rouxen-Y gastric bypass, laparoscopic sleeve gastrectomy, laparoscopic one anastomosis gastric bypass, laparoscopic adjustable gastric banding and laparoscopic biliopancreatic diversion with or without duodenal switch.

Postoperative complications and side effects are common among obese patients. Venous thromboembolism and anastomotic leak are the most fearsome complications. Dumping syndrome occurs in about half of patients after gastric bypass during the first month. Nutritional deficiencies can be developed (mostly deficiencies of vitamin B12 and iron) and an increase in the incidence of gallstones has been observed. ${ }^{60}$

Over the years it has been evident that bariatric surgery restored insulin sensitivity and improved type 2 diabetes, lipid profile and blood pressure control, obstructive sleep apnea, and quality of life. Moreover, retrospective cohort studies have demonstrated that bariatric surgery leads to a decrease in mortality. ${ }^{60,61}$

In most studies, serum uric acid levels were a strong predictor of mortality from cardiovascular disease in healthy middle-aged men. ${ }^{62}$ Other studies suggest that serum uric acid is a strong and independent risk factor for diabetes. ${ }^{63}$

Many studies have demonstrated that weight loss following bariatric surgery resulted in reduced serum uric acid levels in people with obesity and metabolic syndrome. ${ }^{64}$ It seems that weight loss induced a significant reduction in the production of urate, as well as an increased renal clearance of urate. ${ }^{65}$

Furthermore, weight loss following bariatric surgery was found to be associated with reduced inflammatory responses to Monosodium Urate (MSU) crystals, including significant reductions in the production of interleukin- $1 \beta, 6$ and 8 , and TNF $\alpha$ secretion from peripheral blood mononuclear cells. ${ }^{64,66}$ This response could contribute to reduce the risk of gout flares. Indeed, a significant reduction in the frequency of gout attacks after bariatric surgery was observed in many studies. ${ }^{67-69}$ Interestingly, data from some studies revealed that weight loss among patients with uncontrolled gout resulted in a significant suppression in the frequency of gout attacks, regardless of a rather small reduction in serum uric acid levels. Hence, it can be assumed that the weight loss influences the outbreak of the disease through the regulation of inflammatory responses to MSU crystals.

Moreover, it has been shown that adoption of Low-Purine Diet, which is recommended for gout, reduced the risk of gout attacks after bariatric surgery in gout patients. Schiavo et al. ${ }^{69}$ studied the effect of postoperative low-purine diet on the frequency of gout attacks $(\mathrm{n}=24)$, as compared to a normal-purine diet $(\mathrm{n}=16)$ in 40 patients diagnosed with gout before the sleeve gastrectomy procedure. One year after the surgery, a significant decrease in serum uric acid levels was observed in both groups, with a more significant decrease noted in patients following low-purine diet compared to those on a normalpurine diet $(\mathrm{p}<0.001)$. This was also demonstrated by the allopurinol requirements and by the frequency of gout attacks $(p<0.001)$. A year after the sleeve gastrectomy, the low-purine diet group no longer required allopurinol therapy, and suffered no gout attacks. ${ }^{69}$ Thus, bariatric surgery has an indirect effect on decreasing mortality from these chronic diseases, alongside the effect on gout disease.

Table 1 presents studies published over the years in which various types of bariatric surgery in obese gout patients affected serum uric acid levels as well as the frequency of gout attacks.

Gout attacks may develop in the early post-operative period, within 8 days after surgery. Kang et al. compared patients with gout who developed postsurgical gout attacks with patients with gout who did not develop gout attacks after surgery. They discovered that elevated presurgical serum urate levels $(>/=9 \mathrm{mg} / \mathrm{dl})$ and failure to administer colchicine prophylaxis were found to be risk factors for postsurgical gout. Postoperative gout attacks were found in patients who demonstrated higher pre-surgical serum uric acid levels and a more rapid and profound decrease in uric acid levels after surgery. The authors suggested that post-surgical gout attacks could be prevented by controlling pre-surgical uric acid levels. ${ }^{70}$ In a study performed by Friedman et al., ${ }^{71}$ who monitored previous diagnoses of gout patients, $33.3 \%$ of them experienced an acute attack postoperatively. ${ }^{71}$

Nevertheless, some studies have demonstrated that the effect of bariatric surgery on serum uric acid levels and the frequency of gout attacks vary in time after the procedure. Romero-Talamáset et al., ${ }^{72}$ studied 99 bariatric surgery gout patients and compared them to 56 non-bariatric gout patients. Immediately after the surgical procedure, a significantly higher frequency of gout attacks was observed in the bariatric surgery group compared to that observed in patients who underwent other procedures. However, the incidence significantly decreased after the first postoperative month up to 1 year. Remarkably, a significant reduction in serum uric acid levels was observed 13-months after bariatric surgery. ${ }^{72}$ Dalbeth revealed that among obese people with type 2 diabetes and with no history of gout, serum uric acid concentrations increased during the first days after a laparoscopic sleeve gastrectomy and reduced 1 year after surgery. It is thus suggested that the immediate post-surgery rise in serum uric acid levels is due to renal dysfunction associated with the surgery procedure and as a response to surgical tissue disruption, as well as metabolic effects, catabolism, or dehydration from fasting or rapid weight loss. Additionally, dramatic changes in serum uric acid levels might trigger gout attacks. ${ }^{54,64,65}$ 
Table I presents studies published over the years in which various types of bariatric surgery in obese gout patients affected serum uric acid levels as well as the frequency of gout attacks

\begin{tabular}{|c|c|c|c|}
\hline Author, publication, year & Study type & Patients & Results \\
\hline Obes Surg. & Retrospective & obese $(n=40)$ & $\begin{array}{l}\text { One year after the surgery the decrease in serum } \\
\text { uric acid level of the low-purine diet group was more } \\
\text { significant compared to the normal-purine diet group } \\
(p<0.001)\end{array}$ \\
\hline $\begin{array}{l}\text { Maglio } \\
\text { Ann Rheum Dis. } 2017\end{array}$ & Prospective & $\begin{array}{l}\text { obese }(n=398 I) \\
\text { bariatric surgery }(+) n=1982 \\
\text { bariatric surgery }(-) \quad n=1999\end{array}$ & $\begin{array}{l}\text { Bariatric surgery was associated with a reduced } \\
\text { incidence of gout compared with usual care (adjusted } \\
\text { HR } 0.60,95 \% \mathrm{Cl} 0.48 \text { to } 0.75, p<0.00 \text { I) }\end{array}$ \\
\hline $\begin{array}{l}\text { Chen }^{67} \\
\text { Transplant Proc. } 2016\end{array}$ & Retrospective & $\begin{array}{l}\text { morbid obesity, poorly controlled } \\
\text { new-onset diabetes and gout after } \\
\text { kidney transplantation }(n=I)\end{array}$ & Total remission of gout after I year of follow-up \\
\hline $\begin{array}{l}\text { Romero-Talamás }^{72} \\
\text { Surg Obes Relat Dis. } 2014\end{array}$ & Retrospective & $\begin{array}{l}\text { obese, gout } \\
\text { bariatric surgery }(+) n=99 \\
\text { bariatric surgery }(-) n=56\end{array}$ & $\begin{array}{l}\text { The incidence of early gouty attack in the first month } \\
\text { after surgery was significantly higher in the bariatric } \\
\text { group than the nonbariatric group (I7.5\% versus } 1.8 \% \text {, } \\
\mathrm{P}=0.003) \\
\text { In the bariatric group, } 23.8 \% \text { of patients had at least } \\
\text { one gouty attack during the I } 2 \text {-month period before } \\
\text { surgery, which dropped to } 8.0 \% \text { during postoperative } \\
\text { months } \mathrm{I}-\mathrm{I} 3(\mathrm{P}=0.005) \\
\text { There was a significant reduction in uric acid levels } \\
\text { I3-months after bariatric surgery compared with } \\
\text { baseline values }(9.1+/-2.0 \text { versus } 5.6+/-2.5 \mathrm{mg} / \mathrm{dL}, \mathrm{P}= \\
0.007)\end{array}$ \\
\hline $\begin{array}{l}\text { Dalbeth }^{64} \text { Ann } \\
\text { Rheum Dis. } 2014\end{array}$ & Prospective & $\begin{array}{l}\text { obese, type } 2 \text { diabetes }(n=60) \\
\text { gout }(n=12)\end{array}$ & $\begin{array}{l}\text { In gout patients, uric acid serum levels above } \\
\text { therapeutic target levels were reduced from } 83 \% \text { at } \\
\text { baseline to } 33 \% \text { one year after surgery }(p=0.031)\end{array}$ \\
\hline $\begin{array}{l}\text { Dalbeth }^{66} \quad \text { Ann } \\
\text { Rheum Dis. } 2013\end{array}$ & Prospective & $\begin{array}{l}\text { obese, type } 2 \text { diabetes } \\
(n=20)\end{array}$ & $\begin{array}{l}\text { Reduced uric acid serum levels and reduced } \\
\text { inflammatory responses to Monosodium Urate (MSU) } \\
\text { crystals upon mean follow-up of } 256 \text { days }\end{array}$ \\
\hline $\begin{array}{l}\text { Friedman } \\
\text { Surg Obes Relat Dis. } 2008\end{array}$ & Retrospective & $\begin{array}{l}\text { obese }(n=4 I I) \\
\text { gout }(2 I)\end{array}$ & $\begin{array}{l}\text { Only } 33.3 \% \text { of the gout patients had an acute attack } \\
\text { postoperatively }\end{array}$ \\
\hline Obes Surg. & Retrospective & $\begin{array}{l}\text { obese }(n=1,240) \\
\text { gout }(n=5)\end{array}$ & $\begin{array}{l}2 \text { out of gout patients had acute attacks during the } \\
\text { postoperative period }\end{array}$ \\
\hline
\end{tabular}

\section{Conclusion}

In conclusion, the literature contains solid data indicating that obesity is associated with the increased risk of developing gout. Many studies have revealed that weight loss following bariatric surgery resulted in reduced serum uric acid levels and the amelioration of inflammatory responses to MSU crystals. Consequently, a decreased in risk to develop gout as well as lowering the frequency of gout attacks is demonstrated. However, in some of the studies, shortly after the surgery, a rise in serum uric acid levels in addition to a higher incidence of gout attacks was observed, while in the long run ( $\geq 1$ year after the surgery) both serum uric acid levels and incidence of gout attacks were reduced. Thus, in view of these findings we recommend that preoperative prophylactic treatment should be administered to patients with a history of gout. Moreover, serum uric acid levels should be followed shortly after the surgery and treated accordingly in order to prevent an increase in the incidence of gout attacks.

\section{Acknowledgments}

None.

\section{Conflicts of interest}

The author declares there are no conflicts of interest.

\section{References}

1. Robinson PC, Horsburgh S. Gout: Joints and beyond, epidemiology, clinical features, treatment and co-morbidities. Maturitas. 2014;78(4):245-251. 
2. Singh JA, Strand V. Gout is associated with more comorbidities, poorer health-related quality of life and higher healthcare utilization in US veterans. Ann Rheum Dis. 2008;67(9):1310-1316.

3. Edwards NL, Sundy JS, Forsythe A, et al. Work productivity loss due to flares in patients with chronic gout refractory to conventional therapy. $J$ Med Econ. 2011;14(1):10-15.

4. Thottam GE, Krasnokutsky S, Pillinger MH. Gout and Metabolic Syndrome: a Tangled Web. Curr Rheumatol Rep. 2017;19(10):60.

5. McGill NW. The epidemiology and treatment of gout. Open Access Rheumatol. 2011;3:73-82.

6. Sachs L, Batra KL, Zimmermann B. Medical implications of hyperuricemia. Med Health RI. 2009;92(11):353-355.

7. Chaudhary K, Malhotra K, Sowers J, et al. Uric Acid-key ingredient in the recipe for cardiorenal metabolic syndrome. Cardiorenal Med. 2013;3(3):208-220.

8. Soltani Z, Rasheed K, Kapusta DR, et al. Potential role of uric acid in metabolic syndrome, hypertension, kidney injury, and cardiovascular diseases: is it time for reappraisal? Curr Hypertens Rep. 2013;15(3):175181.

9. Joosten LA, Netea MG, Mylona E, et al. Engagement of fatty acids with Tolllike receptor 2 drives interleukin-1beta production via the ASC/ caspase 1 pathway in monosodium urate monohydrate crystal-induced gouty arthritis. Arthritis Rheum. 2010;62(11)3237-3248.

10. Cleophas MC, Crişan TO, Joosten LA. Factors modulating the inflammatory response in acute gouty arthritis. Curr Opin Rheumatol. 2017; 29(2):163-170.

11. Zhu Y, Pandya BJ, Choi HK. Prevalence of gout and hyperuricemia in the US general population: the National Health and Nutrition Examination Survey 2007-2008. Arthritis Rheum. 2011;63(10):3136-3141.

12. Kuo CF, Grainge MJ, Zhang W, Doherty M. Global epidemiology of gout: prevalence, incidence and risk factors. Nat Rev Rheumatol. 2015;11(11):649-662.

13. Wallace KL, Riedel AA, Joseph-Ridge N, Wortmann R. Increasing prevalence of gout and hyperuricemia over 10 years among older adults in a managed care population. J Rheumatol. 2004;31(8):1582-1587.

14. Arromdee E, Michet CJ, Crowson CS, et al. Epidemiology of gout: is the incidence rising? J Rheumatol. 2002;29(11):2403-2406.

15. Chuang SY, Lee SC, Hsieh YT, et al. Trends in hyperuricemia and gout prevalence: nutrition and Health Survey in Taiwan from 1993-1996 to 2005-2008. Asia Pac J Clin Nutr. 2011;20(2):301-308.

16. Hak AE, Choi HK. Menopause, postmenopausal hormone use and serum uric acid levels in US women-the Third National Health and Nutrition Examination Survey. Arthritis Res Ther. 2008;10(5):R116.

17. Aune D, Norat T, Vatten LJ. Body mass index and the risk of gout: a systematic review and dose-response meta-analysis of prospective studies. Eur J Nutr. 2014;53(8):1591-1601.

18. Campion EW, Glynn RJ, DeLabry LO. Asymptomatic hyperuricemia. Risks and consequences in the Normative Aging Study. Am J Med. 1987;82(3):421-426.

19. Roubenoff R, Klag MJ, Mead LA, et al. Incidence and risk factors for gout in white men. JAMA. 1991;266(21):3004-3007.

20. Choi HK, Atkinson K, Karlson EW, et al. Obesity, weight change, hypertension, diuretic use, and risk of gout in men: the health professionals follow-up study. Arch Intern Med. 2005;165(7):742-748.
21. Bhole V, de Vera M, Rahman MM, et al. Epidemiology of gout in women: fifty-two-year follow up of a prospective cohort. Arthritis Rheum. 2010;62(4):1069-1076.

22. Rathmann W, Funkhouser E, Dyer AR, et al. Relations of hyperuricemia with the various components of the insulin resistance syndrome in young black and white adults: the CARDIA study. Coronary Artery Risk Development in Young Adults. Ann Epidemiol. 1998;8(4):250-261.

23. MacFarlane LA, Kim SC. Gout: a review of nonmodifiable and modifiable risk factors. Rheum Dis Clin North Am. 2014;40(4):581-604.

24. Choi HK, Curhan G. Beer, liquor, and wine consumption and serum uric acid level: the Third National Health and Nutrition Examination Survey. Arthritis Rheum. 2004;51(6):1023-1029.

25. Choi HK, Liu S, Curhan G. Intake of purine-rich foods, protein, and dairy products and relationship to serum levels of uric acid: the Third National Health and Nutrition Examination Survey. Arthritis Rheum. 2005;52(1):283-289.

26. Choi HK, Willett W, Curhan G. Fructose-rich beverages and risk of gout in women. JAMA. 2010;304(20):2270-2278.

27. Roddy E, Choi HK Epidemiology of gout. Rheum Dis Clin North Am. 2014;40(2):155-175.

28. Singh JA, Reddy SG, Kundukulam J. Risk factors for gout and prevention: a systematic review of the literature. Curr Opin Rheumatol. 2011;23(2):192-202.

29. Robinson PC, Stamp LK. The management of gout: Much has changed. Aust Fam Physician. 2016;45(5):299-302.

30. Culleton BF, Larson MG, Kannel WB, et al. Serum uric acid and risk for cardiovascular disease and death: the Framingham Heart Study. Ann Intern Med. 1999;131(1):7-13.

31. Cohen SD, Kimmel PL, Neff R, et al. Association of incident gout and mortality in dialysis patients. J Am Soc Nephrol. 2008;19(11):2204-2210.

32. Choi HK, Curhan G. Independent impact of gout on mortality and risk for coronary heart disease. Circulation. 2007;116(8):894-900.

33. Strasak A, Ruttmann E, Brant L, et al. Serum uric acid and risk of cardiovascular mortality: a prospective long-term study of 83,683 Austrian men. Clin Chemistry. 2008;54(2):273-284.

34. Kuo CF, See LC, Luo SF, et al. Gout: an independent risk factor for all-cause and cardiovascular mortality. Rheumatology (Oxford). 2010;49(1):141-146.

35. Roughley MJ, Belcher J, Mallen CD, et al. Gout and risk of chronic kidney disease and nephrolithiasis: meta-analysis of observational studies. Arthritis Res Ther. 2015;17(1):90.

36. Bardin T, Richette P. Impact of comorbidities on gout and hyperuricemia: an update on prevalence and treatment options. BMCMed.2017;15(1):123.

37. Zhang Y, Neogi T, Chen C, et al. Low-dose aspirin use and recurrent gout attacks. Ann Rheum Dis. 2014;73(2):385-390.

38. Stibůrková B, Pavlíková M, Sokolová J, et al. Metabolic syndrome, alcohol consumption and genetic factors are associated with serum uric acid concentration. PLoS One. 2014;9(5):e97646.

39. Choi HK, Ford ES, Li C, et al. Prevalence of the metabolic syndrome in patients with gout: the Third National Health and Nutrition Examination Survey. Arthritis Rheum. 2007;57(1):109-115.

40. Stamp LK, Chapman PT. Gout and its comorbidities: implications for therapy. Rheumatology (Oxford). 2013;52(1):34-44. 
41. Khanna D, Khanna PP, Fitzgerald JD, et al. 2012 American College of Rheumatology guidelines for management of gout. Part 2: Therapy and anti inflammatory prophylaxis of acute gouty arthritis. Arthritis Care Res (Hoboken). 2012;64(10):1447-1461.

42. Richette P, Doherty M, Pascual E, et al. 2016 updated EULAR evidencebased recommendations for the management of gout. Ann Rheum Dis. 2017;76(1):29-42.

43. Qaseem A, Harris RP, Forciea MA. Clinical Guidelines Committee of the American College of Physicians. Management of Acute and Recurrent Gout: A Clinical Practice Guideline from the American College of Physicians. Ann Intern Med. 2017;166(1):58-68.

44. Beyl RN Jr, Hughes L, Morgan S. Update on Importance of Diet in Gout Am J Med. 2016;129(11):1153-1158.

45. Hui M, Carr A, Cameron S, et al. The British Society for Rheumatology Guideline for the Management of Gout. Rheumatology (Oxford) 2017;56(7):1056-1059.

46. Haslam DW, James WP. Obesity. Lancet. 2005;366(9492):1197-1209.

47. Maynard JW, Adams DeMarco MA, Baer AN, et al. Incident gout in women and association with obesity in the Atherosclerosis Risk in Communities (ARIC) Study. Am J Med. 2012;125(7):717.e9-717.e17.

48. ChenJH,Pan WH,HsuCC, etal.Impact of obesity and hypertriglyceridemia on gout development with or without hyperuricemia: a prospective study. Arthritis Care Res (Hoboken). 2013;65(1):133-140.

49. Williams PT. Effects of diet, physical activity and performance, and body weight on incident gout in ostensibly healthy, vigorously active men. $\mathrm{Am}$ J Clin Nutr. 2008;87(5):1480-1487.

50. Zhang Y, Chaisson CE, McAlindon T, et al. The online case-crossover study is a novel approach to study triggers for recurrent disease flares. $J$ Clin Epidemiol. 2007;60(1):50-55.

51. Cea Soriano L, Rothenbacher D, Choi HK, García Rodríguez LA Contemporary epidemiology of gout in the UK general population. Arthritis Res Ther. 2011;13(2):R39.

52. Nguyen UD, Zhang Y, Louie-Gao Q, et al. Obesity Paradox in Recurrent Attacks of Gout in Observational Studies: Clarification and Remedy. Arthritis Care Res (Hoboken). 2017;69(4):561-566.

53. Yamashita S, Matsuzawa Y, Tokunaga K, et al. Studies on the impaired metabolism of uric acid in obese subjects: marked reduction of renal urate excretion and its improvement by a low-calorie diet. Int J Obes. 1986;10(4):255-264

54. Nielsen SM, Bartels EM, Henriksen M, et al. Weight loss for overweight and obese individuals with gout: a systematic review of longitudinal studies. Ann Rheum Dis. 2017;76(11):1870-1882.

55. Schauer PR, Bhatt DL, Kirwan JP, et al. Bariatric surgery versus intensive medical therapy for diabetes--3-year outcomes. $N$ Engl J Med. 2014;370(21):2002-2013.

56. Maciejewski ML, Arterburn DE, Van Scoyoc L, et al. Bariatric Surgery and Long-term Durability of Weight Loss. JAMA Surg. 2016;151(11):10461055 .
57. Lau DC, Douketis JD, Morrison KM, et al. 2006 Canadian clinical practice guidelines on the management and prevention of obesity in adults and children [summary]. CMAJ. 2007;176(Suppl 8):S1-13.

58. Maggard MA, Shugarman LR, Suttorp M, et al. Meta-analysis: surgical treatment of obesity. Ann Intern Med. 2005;142(7):547-559.

59. Sjostrom L, Narbro K, Sjostrom CD, et al. Effects of bariatric surgery on mortality in Swedish obese subjects. $N$ Engl J Med. 2007;357(8):741752.

60. Bult MJ, van Dalen T, Muller AF. Surgical treatment of obesity. Eur $J$ Endocrinol. 2008;158(2):135-145.

61. Mingrone G, Panunzi S, De Gaetano A, et al. Bariatric surgery versus conventional medical therapy for type 2 diabetes. $N$ Engl J Med. 2012;366(17):1577-1585.

62. Niskanen LK, Laaksonen DE, Nyyssönen K, et al. Uric acid level as a risk factor for cardiovascular and all-cause mortality in middle-aged men: a prospective cohort study. Arch Intern Med. 2004;164(14):1546-1551.

63. Dehghan A, van Hoek M, Sijbrands EJ, et al. High serum uric acid as a novel risk factor for type 2 diabetes. Diabetes Care. 2008;31(2):361-362.

64. Dalbeth N, Chen P, White M, et al. Impact of bariatric surgery on serum urate targets in people with morbid obesity and diabetes: a prospective longitudinal study. Ann Rheum Dis. 2014;73(5):797-802.

65. Antozzi P, Soto F, Arias F, et al. Development of acute gouty attack in the morbidly obese population after bariatric surgery. Obes Surg. 2005;15(3):405-407.

66. Dalbeth N, Pool B, Yip S. Effect of bariatric surgery on the inflammatory response to monosodium urate crystals: a prospective study. Ann Rheum Dis. 2013;72(9):1583-1584.

67. Chen JH, Lee CH, Chang CM, et al. Successful Management of NewOnset Diabetes Mellitus and Obesity with the Use of Laparoscopic Sleeve Gastrectomy After Kidney Transplantation-A Case Report. Transplant Proc. 2016;48(3):938-939.

68. Maglio C, Peltonen M, Neovius M, et al. Effects of bariatric surgery on gout incidence in the Swedish Obese Subjects study: a nonrandomized, prospective, controlled intervention trial. Ann Rheum Dis. 2017;76(4):688-693

69. Schiavo L, Favrè G, Pilone V, et al. Low-Purine Diet Is More Effective Than Normal-Purine Diet in Reducing the Risk of Gouty Attacks After Sleeve Gastrectomy in Patients Suffering of Gout Before Surgery: a Retrospective Study. Obes Surg. 2018;28(5):1263-1270.

70. Kang EH, Lee EY, Lee YJ, et al. Clinical features and risk factors of postsurgical gout. Ann Rheum Dis. 2008;67(9):1271-1275.

71. Friedman JE, Dallal RM, Lord JL. Gouty attacks occur frequently in postoperative gastric bypass patients. Surg Obes Relat Dis. 2008;4(1):11-

72. Romero-Talamás H, Daigle CR, Aminian A, et al. The effect of bariatric surgery on gout: a comparative study. Surg Obes Relat Dis. 2014;10(6):1161-1165 